\title{
SISTEM INFORMASI PENGOLAHAN DATA PEMBELIAN DAN PENJUALAN PADA TOKO KOLONCUCU TERNATE
}

\section{INFORMATION SYSTEM OF PURCHASE DATA PROCESSING AND SALES ON KOLONCUCU TERNATE STORES}

\author{
Muhdar Abdurahman \\ Program Studi Komputerisasi Akuntansi, \\ Politeknik Sains dan Teknologi Wiratama Maluku Utara \\ muhdar.abdurahman@gmail.com
}

\begin{abstract}
Abstrak
Meningkatnya operasional organisasi atau perusahaan dalam kegiatan berbisnis tidak terlepas dari penggunaan teknologi informasi, penggunaan teknologi informasi merupakan salah satu langkah yang efektif dalam pengolahan data, maupun transaksi bisnis dengan menggunakan perangkat komputer yang semakin canggih. Toko Koloncucu merupakan salah satu toko di Kota Ternate yang bergerak dalam bidang penjualan peralatan rumah tangga. Proses pendataan pembelian dan penjualan barang di toko ini masih manual, data pembelian dan penjualan barang masih dicatat di dalam buku. Dalam pencatatan transaksi secara manual sering terjadi kesulitan dalam mengontrol stok barang, kesalahan pendataan, proses pencarian nama barang membutuhkan waktu karena harus membuka satu persatu arsip pencatatan pada buku sehingga kurang efektif. Penelitian ini dilakukan di Toko Koloncucu Kota Ternate menggunakan bahasa pemrograman $P H P, M y S Q L$ sebagai database. Dengan adanya sistem ini diharapkan dapat menunjang kinerja dan pelayanan pada Toko Koloncucu, memudahkan pihak Toko mengelola data pembelian dan penjualan.
\end{abstract}

\section{Kata Kunci : Sistem, Informasi, Data Pembelian, Penjualan}

\section{Abstract}

Increased operational organization or company in business activities cannot be separated from the use of information technology, the use of information technology is one of the effective steps in data processing, as well as business transactions using increasingly sophisticated computer devices. Koloncucu Stores is one shop in the City of Ternate which is a form of business engaged in sales the goods in the shop Koloncucu is still manual. Where the data purchase and sale of goods still exist manually in the book, in recording transactions manually often occur in the control of the stock of goods, error logging, the search process name of goods takes time must open one record at one archive the manual makes it less effective. This research was conducted at Koloncucu Stores Ternate City using PHP programming language, MySql as a database, with this system is expected to support performance and service at Koloncucu Stores in facilitating the Store manage data of purchase and sale.

Keyword: Systems, Information, Data Purchase, Sales

\section{PENDAHULUAN}

Meningkatnya operasional organisasi atau perusahaan dalam kegiatan berbisnis tidak terlepas dari teknologi informasi. Penggunaan teknologi informasi merupakan salah satu langkah yang efektif 
dalam pengolahan data, maupun transaksi bisnis dengan menggunakan perangkat komputer yang semakin canggih. Dengan sarana komputer sebagai media kerja akan dapat membantu suatu usaha atau mempermudah pekerjaan yang dijalankan dalam meningktkan produktifitas kerja dan kualitas kinerja, baik dari sumber daya hardware (perangkat keras), software (perangkat lunak) dan branware (manusia). Kemajuan dan kemampuan teknologi informasi memberi solusi jauh lebih baik dibadingkan mengandalkan manusia (konfeksi) karena komputer dengan sebuah sistem yang canggih dapat bekerja secara konsisten (terus-menerus).

Kinerja organisasi atau perusahaan sangat dipengaruhi oleh penguasaan teknologi informasi dari karyawan. Dengan aplikasi teknologi maka organisasi akan mengalami perubahan sistem manajemen, dari sistem tradisional ke sistem manajemen kontemporer. Teknologi informasi berkaitan dengan pelayanan, hal tersebut dikarenakan salah satu dimensi dari kualitas pelayanan adalah kecepatan pelayanan (Parasuraman et al., 1988 dalam Mardjiono, 2009). Dimensi tersebut dapat dikaitkan dengan teknologi informasi. Dengan adanya teknologi informasi, pelayanan yang diberikan khususnya pada organisasi atau perusahaan akan semakin cepat dan akurat.

Pembelian adalah (purchasing) akun yang digunakan untuk mencatat semua pembelian barang dagang dalam suatu periode (Soemarso, 2009). Pembelian merupakan sinonim dari pengadaan, yang diartikan pengadaan adalah proses bisnis memilih sumber, pemesanan dan memperoleh barang dan jasa.

Menurut Kotler (2007) penjualan merupakan proses dimana kebutuhan pembeli dan kebutuhan penjual dipenuhi, melalui antarpertukaran informasi dan kepentingan.

Toko Koloncucu merupakan salah satu toko di Kota Ternate yang bergerak dalam bidang penjualan peralatan rumah tangga. Proses pendataan pembelian dan penjualan barang pada Toko Koloncucu masih manual, dimana data pembelian barang masih dicatat secara manual didalam buku seperti nama supplier, tanggal pengiriman, tanggal jatuh tempo pembayaran, nama barang, harga barang dan jumlah barang yang dipesan. Untuk data penjualan barang pun, karyawan masih mencatat transaksi penjualan barang di dalam buku secara manual. Dalam pencatatan transaksi secara manual sering terjadi kesulitan mengontrol stok barang, kesalahan pendataan, proses pencarian nama barang membutuhkan waktu karena harus membuka satu persatu arsip pencatatan pada buku manual tersebut sehingga kurang efektif.

\section{Rumusan Masalah}

Masalah dalam penilitian ini adalah bagaimana merancang sistem informasi pengelolaan data pembelian dan penjualan barang berbasis web pada Toko Koloncucu ? Dari rumusan masalah penilitian ini bertujuan merancang Sistem Informasi Pengelolahan Data Pembelian dan Penjualan Barang berbasis Web pada Toko Koloncucu Ternate, diharapkan dapat menunjang kinerja dan pelayanan serta memudahkan pihak Toko mengelola data pembelian dan penjualan.

\section{LANDASAN TEORI \\ Pengertian Sistem}

Informasi adalah data yang telah diklarifikasikan oleh atau diinterpretasikan untuk digunakan dalam proses pengambilan keputusan (Sutabri, 2012). 
Menurut Kusrini dan Andri koniyo (2007:7) informasi adalah data yang sudah diolah menjadi sebuah bentuk yang berarti bagi pengguna, yang bermanfaat dalam pengambilan keputusan saat ini atau mendukung sumber informasi. Data belum memiliki nilai, sedangkan informasi sudah memiliki nilai. Informasi dikatakan bernilai bila manfaatnyaa lebih besar dibanding biaya untuk mendapatkannya.

\section{Sistem Informasi}

Tata Sutabri (2012:39) mengatakan sistem informasi terdiri dari komponenkomponen yang disebut dengan istilah blok bangunan, yang terdiri dari blok masukan, blok model, blok keluaran, blok teknologi, blok basis data, dan blok kendali, sebagai suatu sistem. Keenam blok tersebut saling berinteraksi satu dengan yang lain membentuk satu kesatuan untuk mencapai sasaran.

\section{Pembelian}

Pembelian adalah suatu kegiatan untuk memperoleh sejumlah harta atau aktiva maupun jasa dari satu pihak untuk kelangsungan usaha atau kebutuhan yang mendasar, sehingga dilakukan pembayaran atas sejumlah uang atau jasa terebut, untuk kelangsungan operasional perusahaan (Irawati, 2008).

Pembelian adalah (purchasing) akun yang digunakan untuk mencatat semua pembelian barang dagang dalam suatu periode (Soemarso, 2009).

\section{Penjualan}

Penjualan merupakan suatu fungsi yang dianggap sebagai ujung tombak dalam suatu perusahaan karena fungsi itulah perusahaan memperoleh pendapatan, dan kemudian menerima barang yang dibeli. Perusahaan menerima uang tunai, cek pribadi atau pembayaran dengan kartu kredit sebelum barang diserahkan kepada pembeli (Mulyadi, 2010).

\section{Pengertian Web}

Menurut Arief (2011:7) web adalah salah satu aplikasi yang berisikan dokumen-dokumen multimedia (teks, gambar, suara, animasi, video) di dalamnya menggunakan protokol HTTP (hypertext transfer protocol) dan untuk mengaksesnya menggunakan perangkat lunak yang disebut browser.

\section{PhpMyAdmin}

Menurut Nugroho (2010:88) PhpMyAdmin adalah suatu aplikasi open source yang berbasis web. Aplikasi ini dibuat menggunakan program PHP. Fungsi aplikasi ini adalah untuk mengakses database MySQL.

Menurut Nugroho (2013:1), XAMPP adalah paket program web lengkap yang dapat Anda pakai untuk belajar pemrograman web, khususnya PHP dan MySQL.

\section{Pengertian MySQL}

MySQL adalah salah satu jenis database server yang sangat terkenal dan banyak digunakan untuk membangun apliksi web yang menggunakan database sebagai sumber dan pengolahan datanya (Arief, 2011).

MySQL merupakan perangkat lunak yang digunakan untuk membangun database yang sering digunakan di lingkungan linux. MySQL merupakan software open source yang berarti free untuk digunakan. Selain di lingkungan linux, MySQL juga tersedia di lingkungan windows (Sulham, 2007). 


\section{Flowchart}

Flowchart dipergunakan untuk menggambarkan proses kegiatan dalam suatu organisasi. Flowchart berupa bagan untuk keseluruhan sistem termasuk kegiatan-kegiatan manual dan aliran atau arus dokumen yang dipergunakan dalam system.

Flowchart adalah simbol-simbol pekerjaan yang menunjukkan bagan aliran proses yang saling terhubung. Jadi, setiap simbol flowchart melambangkan pekerjaan dan instruksinya. Simbol-simbol flowchart adalah standar yang ditentukan oleh Amerika National Standard Institute Inc. (Community, 2011:16).

\section{DFD (Data Flow Diagram)}

Data Flow Diagram adalah suatu network yang menggambarkan suatu system automat atau komputerisasi, manualisasi, atau gabungan dari keduanya, yang penggambaranya disusun dalam bentuk kumpulan komponen sitem yang saling berhubungan sesuai aturan mainya (Sutabri, 2012:116).

\section{METODE PENELITIAN}

1) Interview adalah suatu metode pengumpulan data dengan cara tanya jawab atau wawancara secara langsung kepada pimpinan dan staf karyawan tentang cara pengolahan data pembelian dan penjualan di Toko Koloncucu.

2) Observasi adalah suatu metode pengumpulan data dimana penelitian dilakukan secara langsung terhadap objek yang akan diteliti.

\section{Kebutuhan Fungsional}

Kebutuhan fungsional adalah kebutuhan-kebutuhan yang memiliki keterkaitan langsung dengan sistem. Kebutuhan fungsional dari sistem ini meliputi, antara lain:

1. Kebutuhan Pengguna
a. Mendapatkan informasi data pembelian dan penjualan
b. Mendapatkan informasi data persediaan barang

2. Kebutuhan administrator
a. Melakukan login ke system
b. Memanagement data base Sistem
c. Mengelola data pembelian, Penjualan dan Persediaan

\section{Kebutuhan Non-Fungsional}

Kebutuhan non-fungsional adalah kebutuhan yang tidak secara langsung terkait dengan fitur tertentu di dalam system, antara lain:

1. Kebutuhan perangkat keras
a. AMD E2-1800 APU with Radeon.
b. Hardisk 297 GB
c. Ram $2.00 \mathrm{~GB}$
d. Printer Cannon Pixma iP 2770

2. Kebutuhan perangkat lunak
a. Sistem Operasi Windows 7 Ultimate.
b. Mysql sebagai media database
c. Microsoft Office 2007 (Ms Word) sebagai pembuatan Hasil laporan
d. Pemrograman menggunakan bahasa HTML, PHP, dan MySQL
e. Microsoft Visio untuk mendesain sistem (Flowchart, DFD,ERD, Rancangan Layout Sistem)
f. Xampp untuk media server
g. Sublime Text Sebagai Editor Script Pemrograman.

\section{Analisa Sistem yang Berjalan}

Sistem yang berjalan pada Toko Koloncucu masih bersifat konvensional, berikut desain flowchart sistem yang berjalan. 


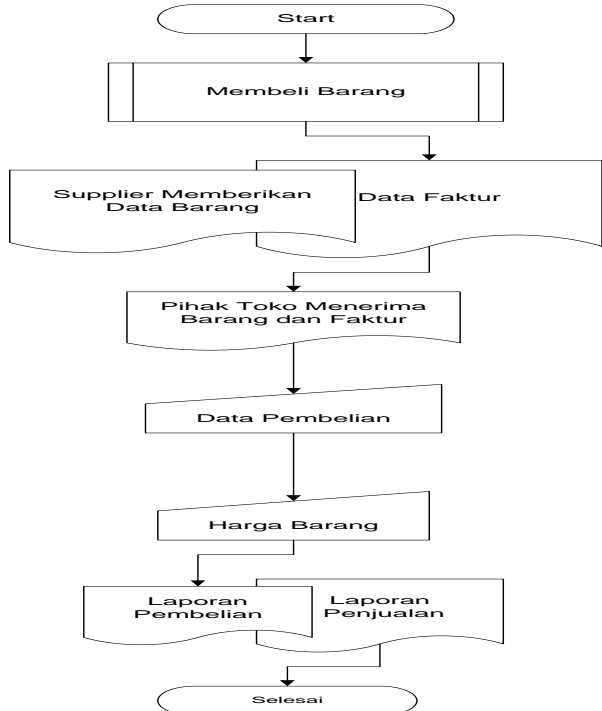

Gambar 1 : Flowchart Sistem Yang berjalan

\section{Rancangan System yang Diusulkan}

Sistem yang diusulkan peneliti berdasarkan identifikasi masalah pada sistem yang berjalan. Berikut desain flowchart sistem yang diusulkan.

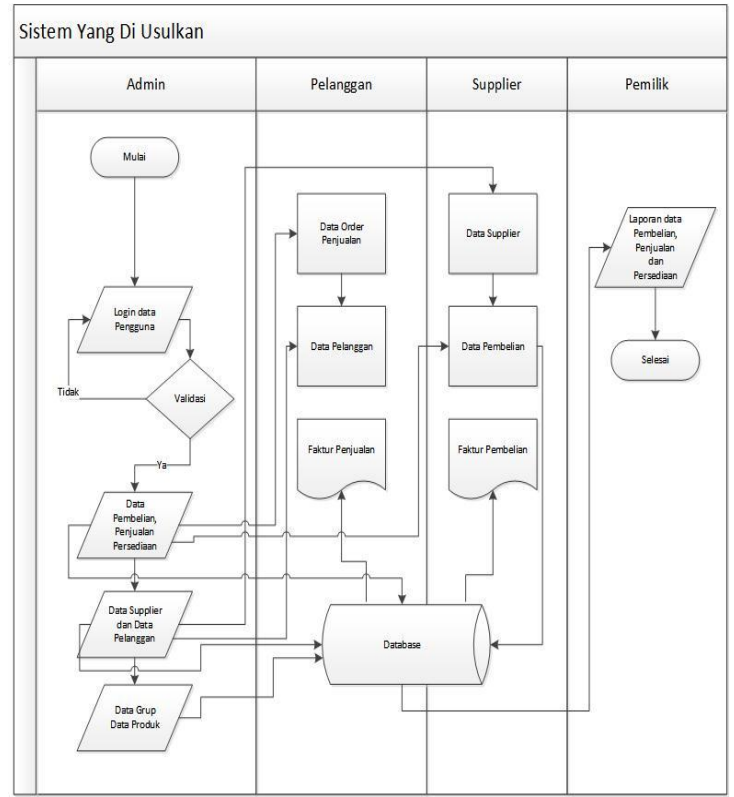

Gambar 2 : Flowchart Sistem Yang diusulkan

PERANCANGAN SISTEM

Perancangan Tabel Database

Databse admin

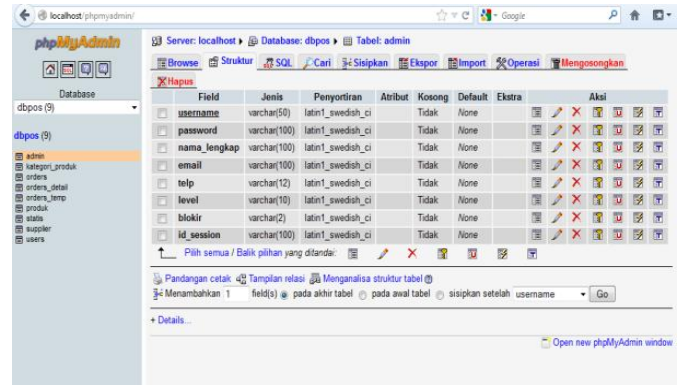

Gambar 3 : Database tabel admin

\section{Database Kategori Produk}

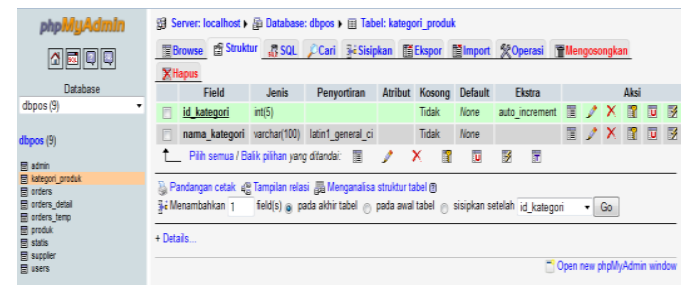

Gambar 4 : Database tabel Kategori Produk

\section{Database Order}

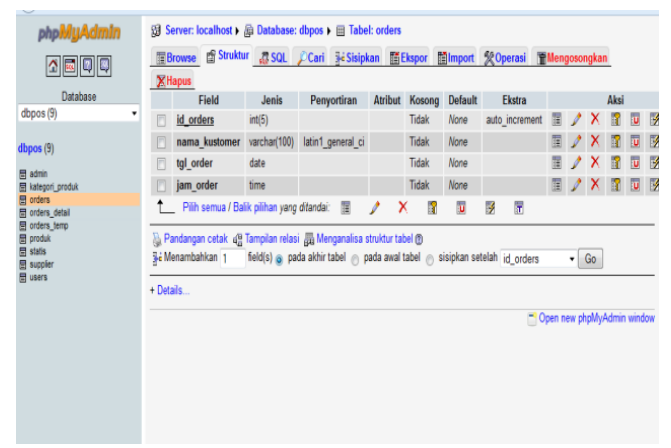

Gambar 5 : Database tabel order

\section{Database Detail Order}

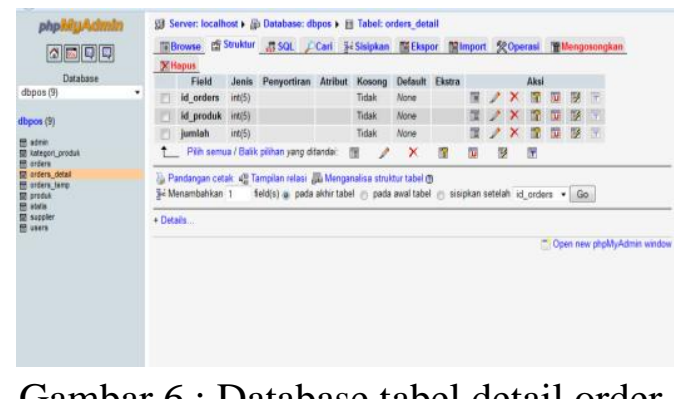

Gambar 6 : Database tabel detail order

\section{Database Order Temp}




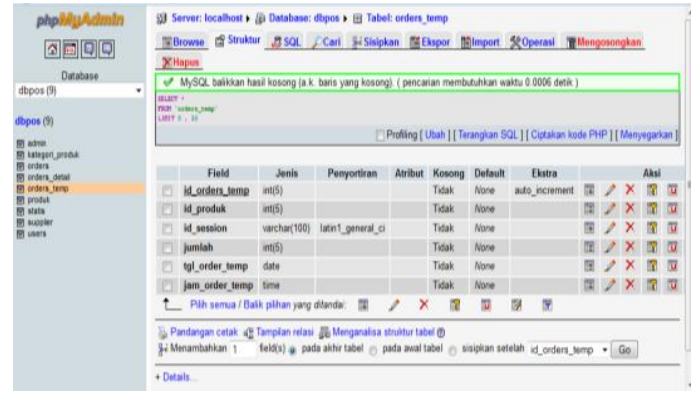

Gambar 7 : Database tabel order temp

\section{Database Produk}

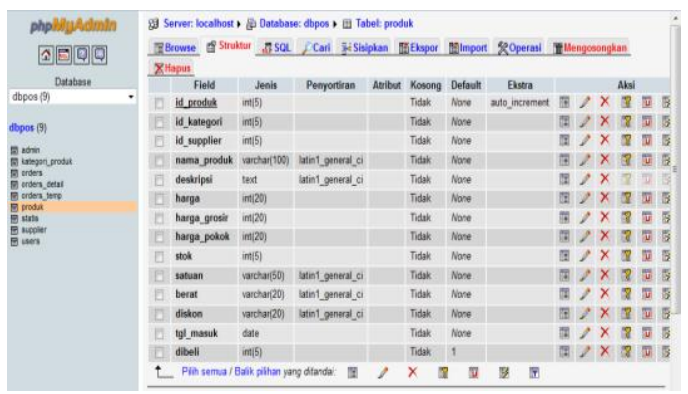

Gambar 8 : Database tabel produk

\section{Database User}

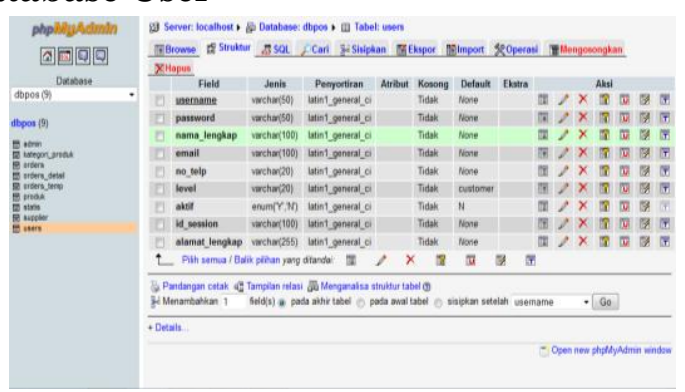

Gambar 9 : Database tabel user

\section{Diagram Konteks}

Diagram Konteks merupakan rancangan alur proses sistem informasi pada Toko Koloncucu. Rancangan sistem diagram konteks alur proses di sajikan sebagai berikut:

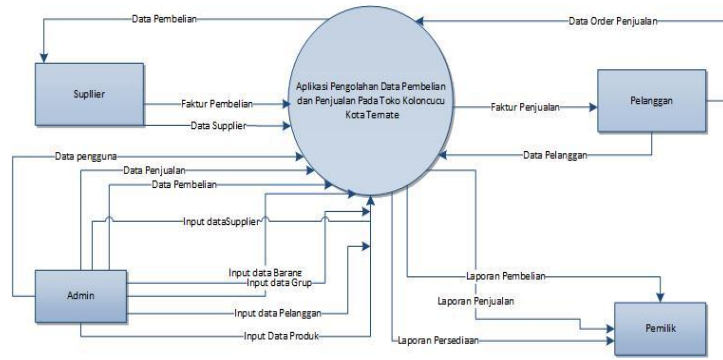

Gambar 10 : Diagram Konteks Sistem

\section{DFD Level 1}

Data Flow Diagram Level 1 merupakan proses detail sistem untuk memudahkan seorang pengelola data melakukan proses pembangunan dan pengembangan sistem.

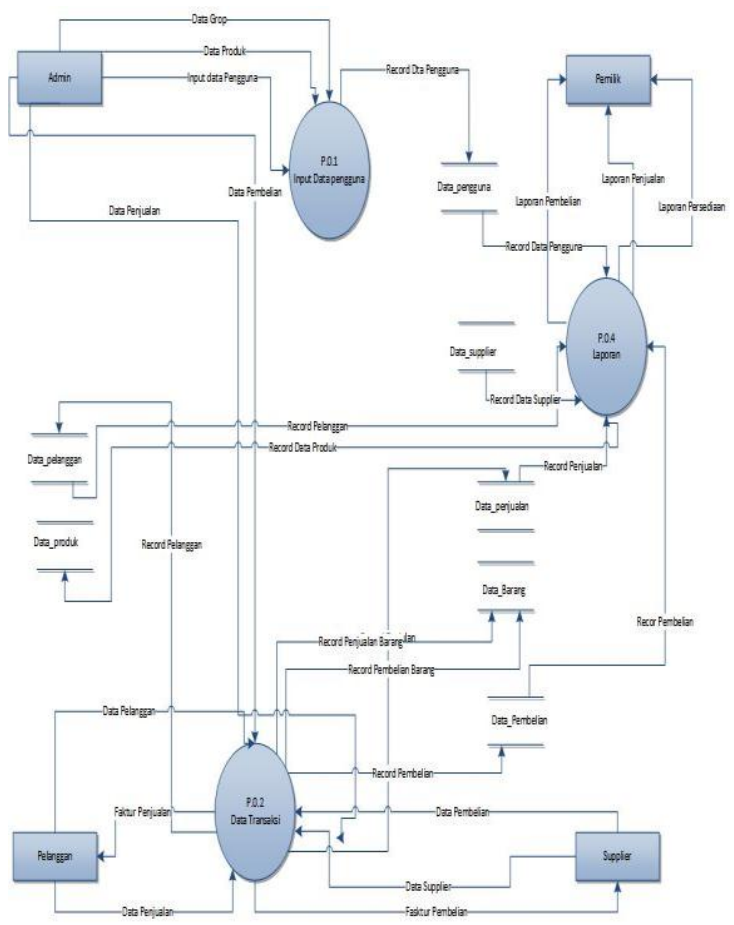

Gambar 11 : DFD Level 1

\section{ERD (Entity Relationship Diagram)}

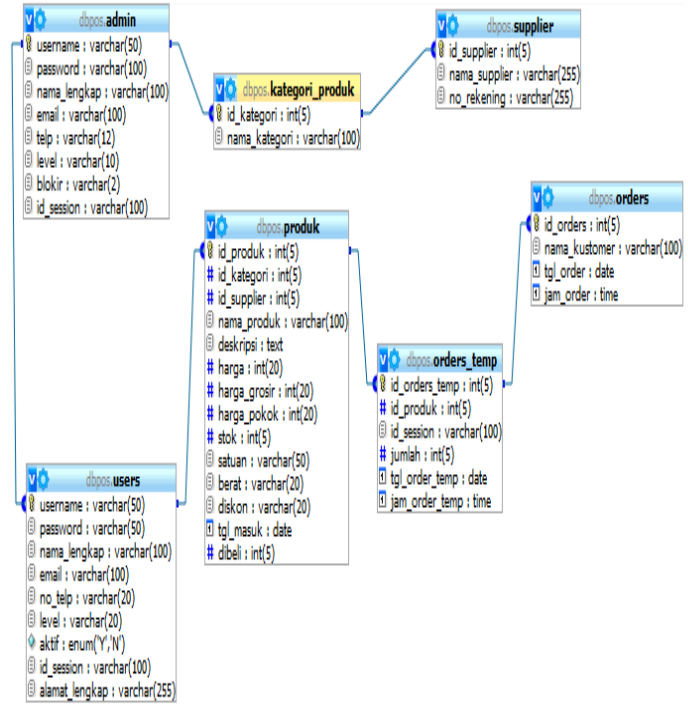

Gambar 12 : ERD Relasi Tabel 


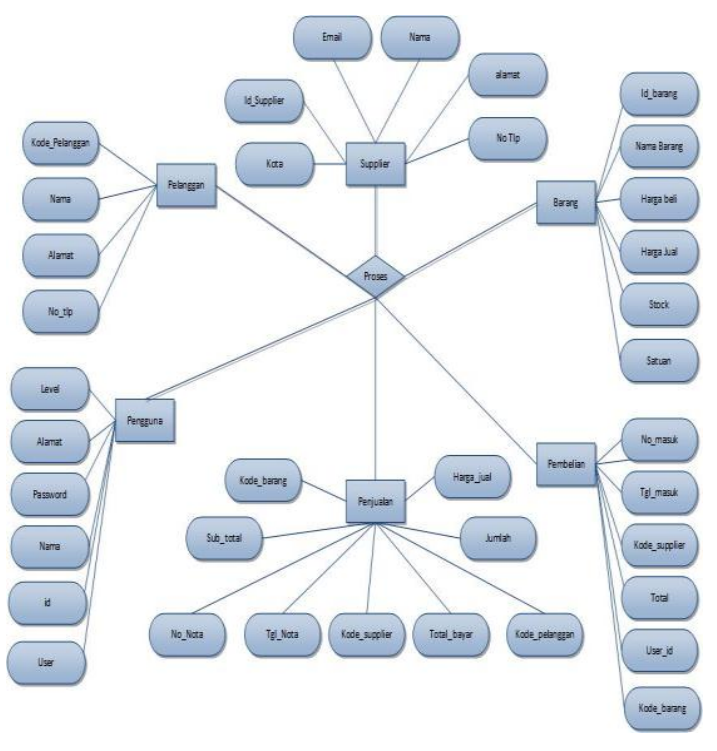

Gambar 13 : ERD Notasi

\section{IMPLEMENTASI SISTEM}

\section{Halaman Menu Login}

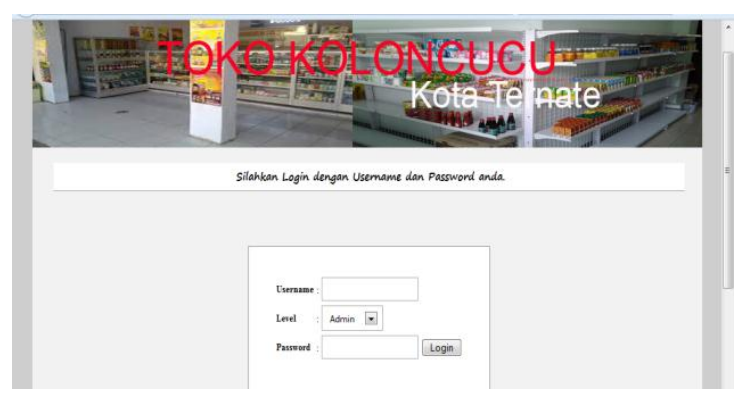

Gambar 14 : Menu Login Admin

\section{Halaman Menu Admin}

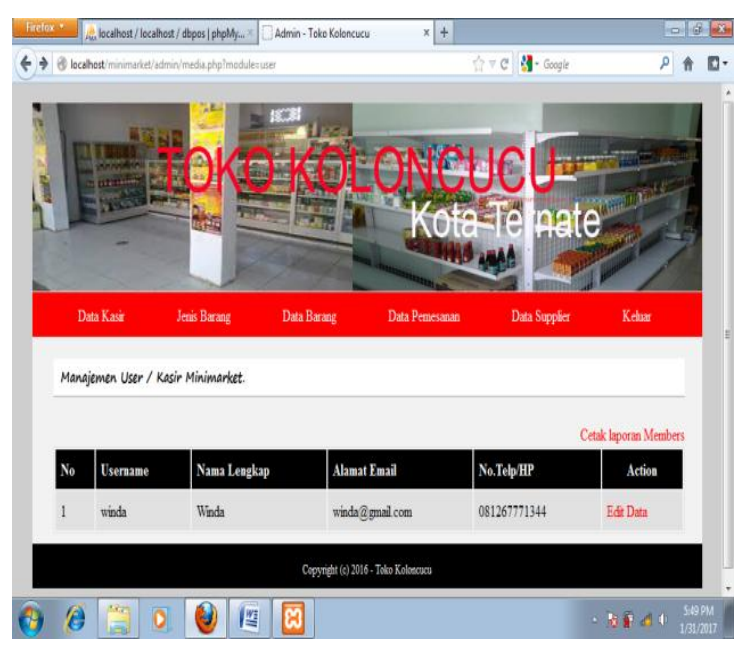

Gambar 15 : Menu Admin

\section{Halaman Menu Jenis Barang}

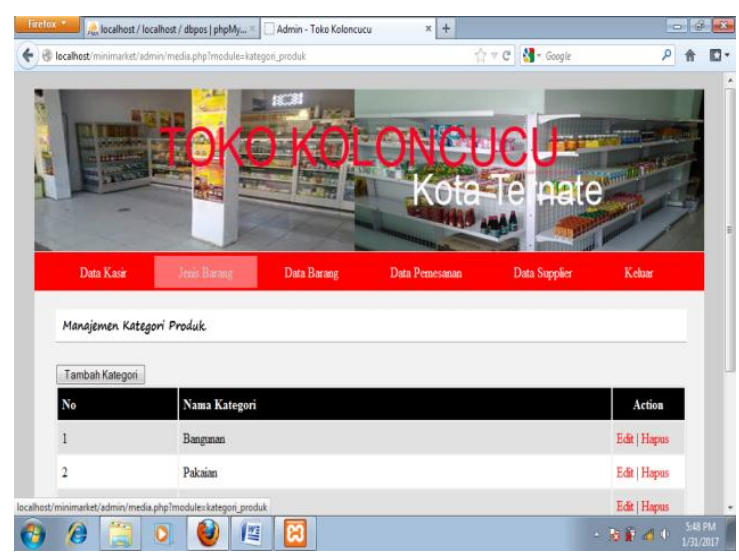

Gambar 16 : Menu Data Dokter

\section{Halaman Menu Data Barang}

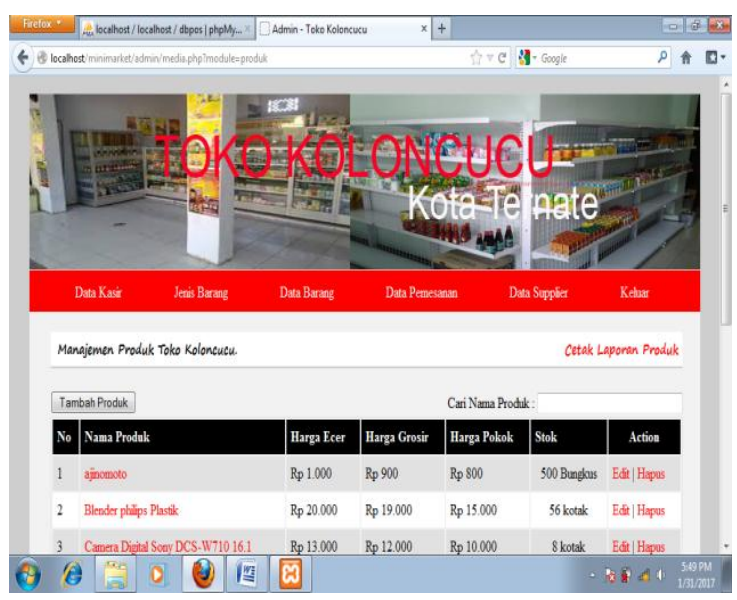

Gambar 17 : Menu Data Barang

\section{Halaman Menu Data Pemesanan}

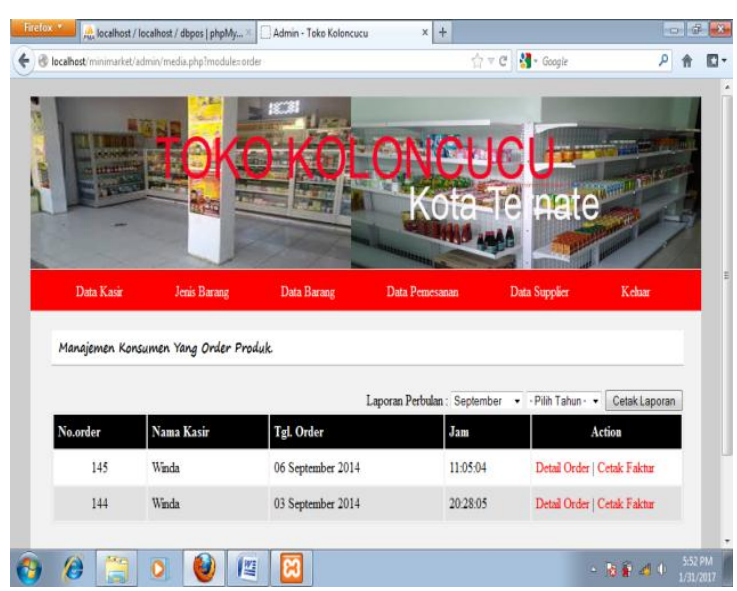


Gambar 18 : Menu Data Pemesanan

\section{Halaman Menu Trasaksi Penjualan}

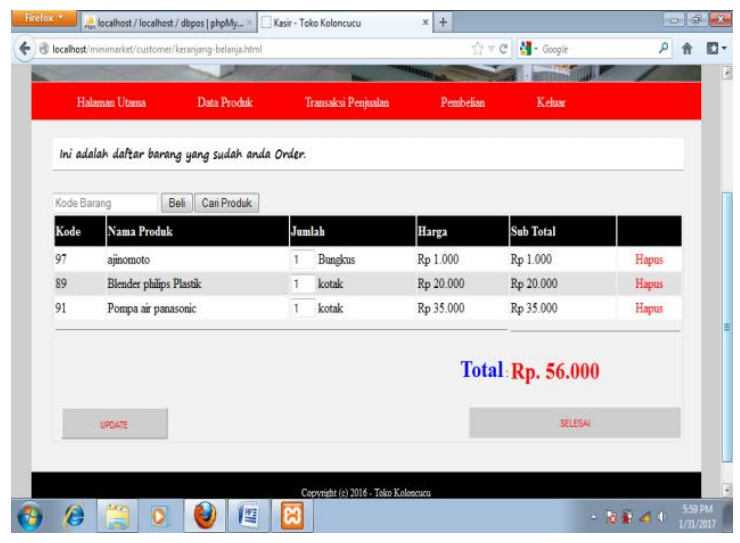

Gambar 19 : Menu Trasaksi Penjualan

\section{Halaman Menu Cetak Transaksi}

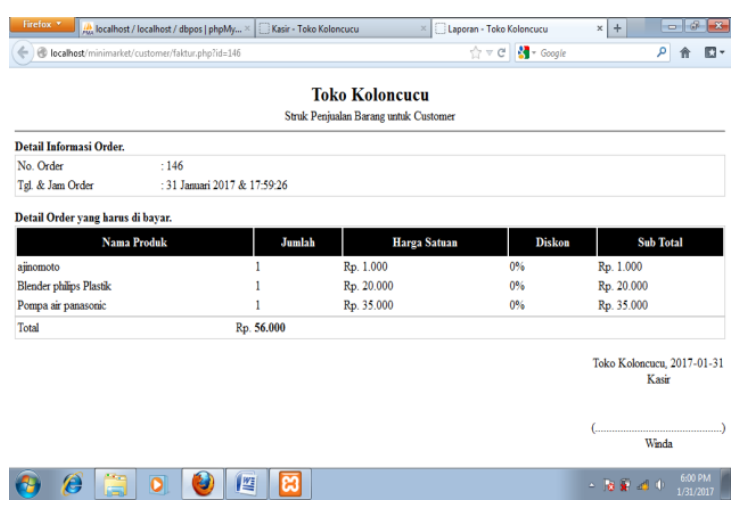

Gambar 20 : Menu Trasaksi Penjualan

\section{Pengujian Sistem}

Tabel 1 : Uji coba Blackbox

\begin{tabular}{|l|l|l|l|}
\hline No & Nama Modul & $\begin{array}{l}\text { Jenis Unit } \\
\text { Yang di Uji }\end{array}$ & $\begin{array}{l}\text { Hasil } \\
\text { Test }\end{array}$ \\
\hline 1 & \multirow{2}{*}{ Form Login } & Login & Sukses \\
\cline { 3 - 4 } & & Keluar & Sukses \\
\hline 2 & \multirow{2}{*}{ Menu Utama } & Data Kasir & Sukses \\
\cline { 3 - 4 } & & Jenis Barang & Sukses \\
\cline { 3 - 4 } & & Data Barang & Sukses \\
\cline { 3 - 4 } & & Data Pemesanan & Sukses \\
\cline { 3 - 4 } & & Data Supplier & Sukses \\
\hline 4 & \multirow{2}{*}{ Data Kasir } & No & Sukses \\
\cline { 3 - 4 } & & User name & Sukses \\
\cline { 3 - 4 } & & Nama Lengkap & Sukses \\
\hline
\end{tabular}

\begin{tabular}{|c|c|c|c|}
\hline & & Email & Sukses \\
\hline & & No Telp & Sukses \\
\hline & & Edit & Sukses \\
\hline 5 & $\begin{array}{l}\text { Menu Jenis } \\
\text { Barang }\end{array}$ & $\begin{array}{l}\text { Tambah } \\
\text { Kategori }\end{array}$ & Sukses \\
\hline & & Edit & Sukses \\
\hline & & Hapus & Sukses \\
\hline 6 & Input Data & Tambah Produk & Sukses \\
\hline & & Nama & Sukses \\
\hline & & Harga & Sukses \\
\hline & & Stok & Sukses \\
\hline & & Cetak & Sukses \\
\hline 8 & Meu Data & Nama Kasir & Sukses \\
\hline & Pemesanan & No Order & Sukses \\
\hline & & Waktu Order & Sukses \\
\hline & & $\begin{array}{l}\text { Cetak Detail } \\
\text { Order }\end{array}$ & Sukses \\
\hline & & Cetak Faktur & Sukses \\
\hline & & Catak Laporan & Sukses \\
\hline & & $\begin{array}{l}\text { Laporan } \\
\text { Perbulan }\end{array}$ & Sukses \\
\hline 9 & $\begin{array}{l}\text { Menu Data } \\
\text { Supplier }\end{array}$ & $\begin{array}{l}\text { Tambah } \\
\text { Supplier }\end{array}$ & Sukses \\
\hline & & No Rek & Sukses \\
\hline & & Edit & Sukses \\
\hline & & Hapus & Sukses \\
\hline 10 & $\begin{array}{l}\text { Form Ubah } \\
\text { Admin }\end{array}$ & $\begin{array}{l}\text { Masukan Nama } \\
\text { Admin }\end{array}$ & Sukses \\
\hline & & Alamat & Sukses \\
\hline & & Email & Sukses \\
\hline & & $\begin{array}{l}\text { Masukan } \\
\text { Password Baru }\end{array}$ & Sukses \\
\hline
\end{tabular}

\section{KESIMPULAN}

Berdasarkan hasil analisis data dan pembahasan, simpulan yang dapat diambil dari penelitian ini yaitu: 1). Sistem ini mempermudah dan mempercepat proses kerja karyawan dalam mendapatkan informasi mengenai supplier, pelanggan, dan informasi data barang. 2). Mempermudah dan mempercepat 
pembuatan catatan transaksi pembelian dan penjualan serta laporan dan faktur.

Berdasarkan kesimpulan tersebut maka diajukan saran sebagai berikut: 1). Perlu adanya infrastruktur jaringan yang mendukung dalam menjalankan sistem ini agar pemilik dapat mengontrol transaksi dan persediaan dimana saja. 2). Perlu pelatihan pada admin, pengguna, dan kasir yang menggunakan sistem ini di Toko Koloncucu agar sistem dapat dijalankan secara maksimal.

\section{DAFTAR PUSTAKA}

Kusrini dan Andri Koniyo. (2007). Tuntunan Praktis Membangun Sistem Informasi Akuntansi dengan Visual Basic \& Microsoft SQL Server. Yogyakarta: Andi

Susan Irawati, 2008, Akuntansi Dasar $1 \&$ 2. Jakarta: Pustaka.

Soemarso. 2009. Akuntansi Suatu Pengantar. Buku ke 2. Edisi 5. Jakarta : Salemba Empat

Mulyadi. 2010. Sistem Akuntansi, Edisi ke-3, Cetakan ke- 5. Salemba Empat, Jakarta.

Arief M Rudianto. 2011. Pemrograman

Web Dinamis menggunakan PHP dan MySQL. C.V ANDI OFFSET. Yogyakarta

Tata Sutabri. 2012. Konsep Sistem Informasi. Andi. Yogyakarta

Community, eWolf. 2012, Indeks Lengkap Syntax / eWolf Community, MediaKom, Yogyakarta

Nugroho, Bunafit. 2013. Dasar Pemograman Web PHP - MySQL dengan Dreamweaver. Yogyakarta: Gava Media

Sugiyono. (2013), Metode Penelitian Kuantitatif, Kualitatif, dan Kombinasi (Mixed Methods), Alfabeta, Bandung
Lukman Gozali, Erwin Gunadhi, Rina Kurniawati. Perancangan Sistem Informasi Penjualan Buku Pada PD. Restu Percetakan, Jurnal Algoritma, ISSN 2302-7339 Vol. 09 No. 25 2012.

Uswatun Hasanah, Sukadi, Perancangan Sistem Informasi Penjualan On Line Pada Toko Kreatif Suncom Pacitan, IJNS-Indonesian Journal on Networking and Security, November 2013, ISSN 2302-5700 http://ijns.org.

Maxi Ma'roep, Penerapan Sistem Informasi Akuntansi Penjualan pada PT Indomobil Surabaya, Jurnal Ekonomi Bisnis Tahun 14, Nomor 3, November 2009, ISSN: 0853-7283.

Vivin Ambar, Arisandy Ambarita, Sistem Informasi Pengolahan data Kelulusan Siswa Non-Formal Berbasis Web Pada Dinas Pendidikan Nasional Kota Ternate, IJIS-Indonesian Journal on Information System, Volume 2 Nomor 1, April 2017, ISSN 25486438 . 